\title{
Weaving Value Judgment into the Tapestry of Science
}

\author{
Matthew J. Brown*
}

I critically analyze Kevin Elliott's $A$ Tapestry of Values in order to tease out his views on the nature and status of values or value judgments in the text. I show there is a tension in Elliott's view that is closely connected to a major lacuna in the philosophical literature on values in science: the need for a better theory of values.

\section{Keywords}

values in science $\bullet$ value judgment $\bullet$ theory of values $\bullet$ Kevin Elliott $\bullet$ noncognitivism $\bullet$ transparency $\bullet$ lexical priority of evidence over values

Part of an author-meets-critics book symposium on A Tapestry of Values: An Introduction to Values in Science by Kevin C. Elliott (Oxford University Press, 2017), with Elliott 2018a and 2018b, Douglas 2018, and Kourany 2018

\section{Introduction}

Kevin Elliott's book, A Tapestry of Values, is not just (as the subtitle suggests) An Introduction to Values in Science, but an excellent one. 1 Elliott builds an engaging and comprehensive account of the need for careful consideration of values in all of the core phases of scientific inquiry, and he builds it around a rich collection of interesting and thickly described cases and examples of values playing both legitimate and illegitimate roles in science. By engaging closely with cases across a wide variety of different sciences, in different contexts, Elliott makes a compelling case that the need for values in science is widespread.

Out of his discussion, two primary normative reasons for the value-ladenness of science emerge, one based on choices and the other based on aims. Three conditions for the legitimate use of values in science are also proposed-transparency, representation, and engagement-each of which, as norms for values in science, have much to recommend them. These unifying themes emerge again and again from the examples.

\footnotetext{
${ }^{1}$ All parenthetical references, unless otherwise noted, are to Kevin C. Elliott (2017).
}

* Center for Values in Medicine, Science, and Technology, The University of Texas at Dallas, 800 W. Campbell Rd, JO 31, Richardson, Texas, 75080 USA, mattbrown@utdallas.edu 
Elliott tells us in his introduction that he wishes to "minimize complicated conceptual arguments" and avoid as far as possible "philosophical details" that the reader may find "particularly tiresome" (11). It is with apologies, then, that I will proceed to focus entirely on such details and arguments. I will focus on questions related to the nature and status of values or value judgments, in hopes that it will both reveal something interesting about Elliott's account as well as help identify a lacuna in the field of values in science that remains to be adequately filled.

\section{The Need for a Better Theory of Values}

My primary complaint about the accounts of values in science to be found in the literature is that, by and large, they do not take values seriously enough. That is a strong statement to make about philosophies of science which place values into the heart of scientific practice and inquiry, so it will require a little explanation. Despite the fact that recognition of the need for values in science is increasingly widespread, my claim is that most proponents of values in science lack an adequate account of values and that they tend to incorporate implausible views of values into their accounts, at least implicitly.

Consider three popular theories of values in science: the underdetermination-based account (Longino 1990; Nelson 1990; Intemann 2005), Heather Douglas's role-restriction account (Douglas 2009, 2016), and Dan Steel's epistemic priority account (Steel 2010, 2017). On the first, values play the role of filling the gap between evidence and hypothesis created by underdetermination. On the second, values play an indirect role in managing uncertainty or inductive risk by determining standards of evidence. On the third, social, ethical, political, and other values can legimately influence science only after epistemic standards like empirical adequacy, precision, and simplicity have been considered. Despite the significant differences between these accounts, I have argued that each is committed to a version of the lexical priority of evidence over values, according to which epistemic considerations systematically outweigh considerations of values (Brown 2013).

Despite the fact that each of these accounts makes significant room for values in the heart of science, their commitment to lexical priority means that they do not take values seriously enough; that is, they do not have an adequate account of values. The lexical priority principle is only plausible if values have no independent epistemic standing or cognitive status, or they have a systematically inferior sort of status. But this view either amounts to or is plausible because of an implicit noncognitivism about values. This kind of noncognitivism is an implausible commitment for the defender of values in science, because, as Elizabeth Anderson argues, the ideas that science is value-free and values are evidence-free stand or fall together (Anderson 2004).

Returning to the topic at hand: the question I primarily want to ask about $A$ Tapestry of Values is, What is its theory of values? Does it also presuppose implausible, implicit assumptions about values? Answering this question is a bit of an interpretive task, as Elliott does not address it head-on in the book. I will start by looking at some of the general claims that Elliott makes about values. Then I will consider each of Elliott's three conditions for the appropriate use of values in science - transparency, representativeness, and engagement - and what they tell us about how Elliott thinks about values. Finally, I will point towards the need for a more robust account of value judgment.

\section{Some General Claims about Values in Tapestry}

Elliott tells us that, "Broadly speaking, a value is something that is desirable or worthy of pursuit" (11). The precise terminology is important here, because there is a world of difference between 
that which is desired and that which is desirable, or between that which is pursued and that which is worthy of pursuit. This is something that Elliott crucially gets right from the outset. But the overall picture is muddied by several other factors: immediately after providing this very good definition of values, he focuses on examples of what scientists, in fact, tend to value, and he introduces "the problem of wishful thinking," which is difficult to get off the ground as a general problem of values in science unless one thinks of values as mere desires or wishes. Talking about "values" using expression "our values," which the book does frequently, is also at best ambiguous, and at worst suggests an emphasis on what "our society" (whoever that is) currently desires or wishes. It raises a worry that, for Elliott, what is genuinely valuable is just what most of us happen to value.

In previous work, Elliott has been a leading advocate for what has been called the "aims approach" to values in science, and this aspect of his work comes through most clearly in Chapter 4. One of the two major reasons that values must play a role in science is that "they can help scientists to achieve legitimate goals" (14). Goals, of course, are themselves a certain type of future-directed value, and it would make sense that there would be other values instrumental to those goals. Notice that Elliott again sorts the legitimate goals from the (presumably) illegitimate ones, marking again the crucial distinction between what happens to be valued and what is genuinely valuable.

Elliott is less clear about how, exactly, to distinguish the right, or the legitimate, or the genuinely valuable values from the wrong, illegitimate, or merely prima facie values. One general worry about the aims approach is that, without such an account, it becomes a form of noncognitivism or relativism according to which only instrumental values can be assessed, whereas aims or goals must be taken for granted. All that is left, to quote Elliott, "is to clarify the overall goal that we are aiming to achieve" (68). That is, the ends must be taken for granted, and all we can do is get clear about them. But, obviously, clarification is not the same as evaluation of the actual worth of a thing. If Elliott has resources to avoid this problem, it must be in the application of his three conditions of transparency, representativeness, and engagement; I will turn to these next.

\section{Transparency}

The first of Elliott's three conditions to the appropriate use of values in science is that "value influences should be made as transparent as possible" (10). Does a particular view of values sit behind this condition of transparency? Several rationales behind the transparency condition are given in the book, and they suggest somewhat different approaches to this question. In one case, Elliott claims that "scientists should be as transparent as possible about their data, methods, models, and assumptions so that others can identify the ways in which their work supports or is influenced by particular values" (14). The way I read this, scientists should be transparent about values for the same reason they should be transparent about their methods of data collection or the details of their data analysis - so that they can be subjected to scrutiny in the organized, skeptical assessment process that constitutes scientific credibility. If anything, this suggests that values can be the subject of genuinely better and worse judgments.

Elsewhere in the book, Elliott claims that "crucial methodological choices and assumptions typically need to be acknowledged transparently and honestly so that others can determine if they agree with the value implications of those choices" (105, my emphasis). This recalls the problematic emphasis on "our values" and the lingering suggestion of a noncognitivism or relativism about values. Why else would agreement be the right standard for whether the right values were in use? 
A further justification for the transparency condition is that it allows for what Elliott (along with Daniel McKaughan) call "backtracking" (McKaughan and Elliott 2013). Backtracking happens when scientists are transparent about the role of values in science in such a way that listeners can explore alternative interpretations by plugging in different values. (In the book, this is connected especially with ways of framing science communication.) In this way, Elliott seems to align himself with the "cartographic" approach to science advising of Edenhofer and Kowarsh, according to which science advisors should chart multiple pathways through science and policy according to different values (Edenhofer and Kowarsch 2015), as well as with Roger Pielke, Jr.'s "honest broker" approach, according to which scientists should be in the business of multiplying options based on different values (Pielke Jr. 2007). Both of these approaches attempt to disentangle values from expert judgment, and Elliott here seems to do something similar. Such approaches show a real ambivalence towards the idea that scientists make value judgments, and they have been the subject of criticism by opponents of the value-free ideal (Brown and Havstad 2017).

A further worry is how the norm of transparency will impact the public credibility of science. In a recent empirical study conducted by in part by Elliott himself, he and his coauthors found "at least preliminary evidence that acknowledging values may reduce the perceived credibility of scientists within the general public" (Kevin C. Elliott et al. 2017). Their results were certainly complicated, and there is still room to make a normative argument for transparency as well as for a shift in public perceptions of what makes science credible. But it does raise a concern. The concern is further exacerbated by the political tactics involved in exploiting openness, which we can see in the cases of ClimateGate and in neoliberal abuses of Open Data initiatives to defend austerity measures.

\section{Representation}

The most ambivalent condition in Elliott's book is the condition of representativeness. Here are a few representative quotations:

- "[value influences] should be representative of our major social and ethical priorities" (10)

- "When clear, widely recognized ethical principles are available, they should be used to guide the values that influence science. When ethical principles are less settled, science should be influenced as much as possible by values that represent broad societal priorities." $(14-15)$

- "values influencing our research enterprise should adequately represent fundamental ethical principles and, when those do not settle the matter, the values of those who will be affected by the research." (106)

Here's the question that I think Elliott wants the condition of representativeness to answer: Have we got the right values? But philosophers of science are a bit chary of talking that way about values. Hence the way that the condition turns on agreement - either we appeal to settled or accepted fundamental ethical principles, or we turn democratic and leave it up to society or to the relevant stakeholders. Either way, it seems like what matters is the agreement on values (though one could put more emphasis on the fundamental in "fundamental ethical principles" to get a different interpretation). 2

\footnotetext{
${ }^{2}$ Suppose we pursue that alternative line of interpretation, according to which the representation criterion is satisfied if we are using the truly fundamental ethical principles. As it happens, I think there are serious difficulties with that approach as well. Many thinkers have raised the question of whether fundamental ethical principles or
} 
In the current context, it seems highly problematic to hang one's account of the right values on social acceptance or agreement, however broad, without at least the right sort of account of how that agreement is reached. That is, I think it is a mistake to regard as valuable those things that happen to be valued or desired, even by a majority of stakeholders or citizens. There are many ways to see this point, but my favorite is the argument of Herbert Marcuse in One-Dimensional Man: "A comfortable, smooth, reasonable, democratic unfreedom prevails in advanced industrial civilization, a token of technical progress" (Marcuse 1964, 1). Marcuse illustrates the compatibility of democracy and totalitarianism "through the manipulation of needs by vested interests" (3). According to Marcuse, many of the things we happen to desire are what Marcuse calls "false needs":

We may distinguish both true and false needs. "False" are those which are superimposed upon the individual by particular social interests in his repression: the needs which perpetuate toil, aggressiveness, misery, and injustice. Their satisfaction might be most gratifying to the individual, but this happiness is not a condition which has to be maintained and protected if it serves to arrest the development of the ability (his own and others) to recognize the disease of the whole and grasp the chances of curing the disease. The result then is euphoria in unhappiness. Most of the prevailing needs to relax, to bave fun, to behave and consume in accordance with the advertisements, to love and hate what others love and hate, belong to this category of false needs. (Marcuse 1964, 4-5, my emphasis)

According to Marcuse, through inculcation of false needs, democracy becomes "the most efficient system of domination" (56). How many dictatorships and totalitarian regimes are there in the world today that don't at least go through the motions of holding elections? In a context where "broad social priorities" consist of desires conditioned by oppressive social structures, we should worry about being representative of such priorities. In any case, it is hard to see any broad agreement on shared social priorities in America today.

The response to this problem should not be to become less democratic, but to become more democratic, as well as more critical and imaginative. Even John Dewey, the philosopher of democracy, recognized that the mere existence of consultation or voting did not amount to genuine democracy. Democracy also requires cultivated a free and well-educated citizenry, as well as adopting democratic ends, attitudes, and the democratic faith in human equality and the power of human collaboration.

\section{Engagement}

A reasonable objection to the way I've read Elliott's account of the representativeness condition is that I have ignored the way that it interacts with the engagement condition. As Elliott says, "[value influences] should be scrutinized through appropriate processes of engagement between different scholars and other stakeholders" (10). Again, quoting Elliott, "This engagement helps to facilitate both of the other conditions - transparency and representativeness - by promoting thoughtful scrutiny of values in science" (15). It is through the right processes of engagement that the Deweyan conditions on democratic representativeness will arrive at the right values.

In the book, especially in Chapter 7, Elliott provides many powerful examples of engagement between scientists on the one hand and citizens, stakeholders, activists, humanists, other

ultimate normative ethical theories are sufficient for applied ethics. Unfortunately, I don't have the time here to pursue that further. 
scientists, and legal institutions on the other, in ways that seem intuitively to improve the use of values in science. Elliott does not in the end give us a general framework or generalizable model of engagement, but I don't think we should really expect one. The plurality of approaches suited to different situations is probably a better way to think about it than looking for a unified framework. The real trouble I see here is that Elliott gives us no conditions for determining when engagement has been successful or unsuccessful. Is it when scientists and stakeholders agree on the values and how to use them? Is it when scientists use the values they are told to use? Or is it when they get the right values? (And how would we know?)

\section{Conclusion: Towards a Substantive Account of Value Judgment}

In the end, the question I have brought to $A$ Tapestry of Values is not really a question that Elliott sets out to answer. Perhaps it is no wonder that where the book says something relevant, it seems to pull in different directions, and it seems unfair to criticize the book on that account. Still, I find the fact that it does pull us in different directions an interesting fact about the book. The first main direction that Elliott's talk of "values" pulls in is towards the need for a substantive account of values, which allows us to distinguish the genuinely desirable from the merely desired, that is, one that can help us figure out which goals are legitimate and which values are right. The second direction is towards a deflationary or noncognitivist view where the right values are just the desires that are broadly held or widely agreed upon. I believe that the right account of values will follow the first direction, while embracing the motivations for the second direction in a way that does not amount to a deflationary view.

I do not have the space here to defend such an account of values. I can mention a few things that such an account would have, most of which can be found in John Dewey's writings on ethics and valuation. The first I have already emphasized repeatedly. It is the centrally important distinction between what we habitually or currently value and what we judge to be genuinely valuable. We should, however, resist falling into a form of moral fundamentalism or absolutism, focusing instead on providing an account of the process of intelligent inquiry into values. That account should involve consultation of and deliberation with stakeholders, but cannot rest at merely polling them or arriving at agreement. Finally, the account of values should be packaged into a practical ideal that can replace the ideal of value-free science.

In such an account, there would be room for forms of transparency, representativeness, and engagement as instruments to getting values right. I have told you why I do not think these three conditions together can be sufficient, nor does it seem to me that individually any are necessary in every context.

Like most other writers on values in science, Elliott by and large takes values themselves for granted, and is concerned with (1) showing that they have a role to play in science and (2) adjudicating whether their use in science is legitimate or illegitimate. Within this frame, Elliott does the first very well, and raises some important ideas about how to do the second. The latter, however, is limited for lack of a proper account of value judgment that allows us to judge which values are right or best in a particular case. This is, I think, the most important consideration for determining whether the use of values is legitimate. At least, it is the least well explored consideration, and it is one that plays an ambivalent role in Elliott's nonetheless excellent book.

\section{Acknowledgments}

I would like to thank Elyse Purcell for proposing an Author-meets-Critic session at the 2018 Central APA meeting on Kevin's book, my co-symposiasts, and the audience at the session for their comments. 


\section{Literature cited}

Anderson, Elizabeth. 2004. "Uses of Value Judgments in Science: A General Argument, with Lessons from a Case Study of Feminist Research on Divorce." Hypatia 19 (1): 1-24.

Brown, Matthew J. 2013. "Values in Science Beyond Underdetermination and Inductive Risk." Philosophy of Science 80 (5): 829-39.

Brown, Matthew J., and Joyce C. Havstad. 2017. "Inductive Risk, Deferred Decisions, and Climate Science Advising." In Exploring Inductive Risk, edited by Kevin Elliott and Ted Richards, 101-23. Oxford University Press.

Douglas, Heather. 2009. Science, Policy, and the Value-Free Ideal. Pittsburgh: University of Pittsburgh Press.

—. 2016. "Values in Science." In The Oxford Handbook of Philosophy of Science, edited by Paul Humphreys. Oxford University Press.

Douglas, Heather. 2018. "From Tapestry to Loom: Broadening the Perspective on Values in Science." Philosophy, Theory, and Practice in Biology 10 (8). https://doi.org/10.3998/ptpbio.16039257.0010. 008 .

Edenhofer, Ottmar, and Martin Kowarsch. 2015. "Cartography of Pathways: A New Model for Environmental Policy Assessments.” Environmental Science E Policy 51: 56-64.

Elliott, Kevin C. 2017. A Tapestry of Values: An Introduction to Values in Science. Oxford University Press.

Elliott, Kevin C. 2018a. "Précis of A Tapestry of Values: An Introduction to Values in Science." Philosophy, Theory, and Practice in Biology 10 (7). https://doi.org/10.3998/ptpbio.16039257.0010.007.

Elliott, Kevin C. 2018b. "A Tapestry of Values: Response to My Critics." Philosophy, Theory, and Practice in Biology 10 (11). https://doi.org/10.3998/ptpbio.16039257.0010.011.

Elliott, Kevin C., Aaron M. McCright, Summer Allen, and Thomas Dietz. 2017. "Values in Environmental Research: Citizens' Views of Scientists Who Acknowledge Values.” PLOS ONE 12 (10): 1-18. https://doi.org/10.1371/journal.pone.0186049.

Intemann, Kristen. 2005. "Feminism, Underdetermination, and Values in Science." Philosophy of Science 72 (5): 1001-12.

Kourany, Janet A. 2018. "Adding to the Tapestry." Philosophy, Theory, and Practice in Biology 10 (9). https://doi.org/10.3998/ptpbio.16039257.0010.009.

Longino, Helen E. 1990. Science as Social Knowledge: Values and Objectivity in Scientific Inquiry. Princeton, N.J.: Princeton University Press.

Marcuse, Herbert. 1964. One-Dimensional Man: Studies in the Ideology of Advanced Industrial Society. Boston: Beacon Press.

McKaughan, Daniel J., and Kevin C. Elliott. 2013. "Backtracking and the Ethics of Framing: Lessons from Voles and Vasopressin." Accountability in Research 20 (3): 206-26. https://doi.org/10.1080/ 08989621.2013.788384.

Nelson, Lynn Hankinson. 1990. Who Knows: From Quine to a Feminist Empiricism. Philadelphia: Temple University Press.

Pielke Jr., Roger A. 2007. The Honest Broker: Making Sense of Science in Policy and Politics. Cambridge: Cambridge University Press.

Steel, Daniel. 2010. "Epistemic Values and the Argument from Inductive Risk." Philosophy of Science 77 (1): 14-34. 
2017. "Qualified Epistemic Priority: Comparing Two Approaches to Values in Science." In Current Controversies in Values and Science, edited by Kevin Elliott and Daniel Steel, 49-63. Routledge.

(C) 2018 Author(s)

This is an open-access article distributed under the terms of the Creative Commons AttributionNonCommercial-NoDerivatives 4.0 International license, which permits anyone to download, copy, distribute, or display the full text without asking for permission, provided that the creator(s) are given full credit, no derivative works are created, and the work is not used for commercial purposes.

ISSN 2475-3025 